\title{
The femoral sulcus in total knee arthroplasty
}

\author{
Jean-Yves Jenny
}

Received: 5 August 2009/ Accepted: 8 January 2010/Published online: 4 February 2010

(C) Springer-Verlag 2010

Dear Editors,

I would like to comment on the paper by Lingaraj and Bartlett, "The femoral sulcus in total knee arthroplasty"[1].

As far as I understood, the location of the femoral sulcus was defined by palpation of the trochlear groove. The authors observed a mean difference between the location of the sulcus and the midline of the femoral condyles was $0.7 \mathrm{~mm} \pm 1.4 \mathrm{~mm}$.

The accuracy of a measurement system is the degree of closeness of measurements of a quantity to its actual (true) value. The precision of a measurement system, also called reproducibility or repeatability, is the degree to which repeated measurements under unchanged conditions show the same results [2]. Although the two words can be synonymous in colloquial use, they are deliberately contrasted in the context of scientific method. Ideally, a measurement technique is both accurate and precise, with measurements all close to and tightly clustered around the known value. The accuracy and precision of a measurement process is usually established by repeatedly measuring some traceable reference standard.

In the present study, the authors used two different measurement techniques. Both techniques cannot claim that they are completely precise and accurate. I am not aware of previous studies having defined their precision and their accuracy. It would not seem unfair to consider that both techniques involve a $0.5-\mathrm{mm}$ precision and accuracy. That means that the global precision and accuracy of the study might be about $1 \mathrm{~mm}$. That means that the mean difference observed was of the same magnitude that the presumed variability of the measurements techniques.

In other words, the difference observed in the present study might be due to an actual difference, but might also be only due to the inherent inaccuracy of the measurement techniques. This statement may jeopardize the relevance of the use of the proposed landmark.

\section{References}

1. Lingaraj K, Bartlett J (2009) The femoral sulcus in total knee arthroplasty. Knee Surg Sports Traumatol Arthrosc 17:499-502

2. Taylor JR (1999) An introduction to error analysis: the study of uncertainties in physical measurements. University Science Books, California, pp 128-129 